\title{
FTIR Spectroscopy as a novel analytical approach for investigation of glucose transport and glucose transport inhibition studies in transwell in vitro barrier models
}

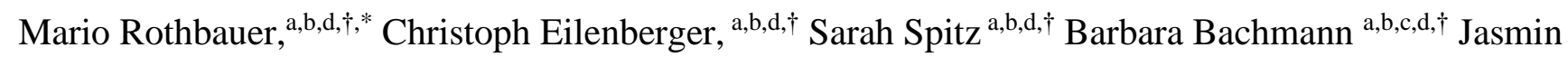
Pajenda ${ }^{\mathrm{a}, \mathrm{b}, \mathrm{d}}$ Andreas Schwaighofer, ${ }^{\mathrm{a}}$ Gregor Höll, ${ }^{\mathrm{a}, \mathrm{b}, \mathrm{d}}$, Palle Steen Helmke, ${ }^{\mathrm{a}, \mathrm{b}, \mathrm{d}}$ Yvonne Kohl, ${ }^{\mathrm{e}}$ Bernhard Lendl, and Peter Ertl a,b,d,*

a Institute of Chemical Technologies and Analytics, Vienna University of Technology, Getreidemarkt 9, 1060 Vienna, Austria.

b Institute of Applied Synthetic Chemistry, Vienna University of Technology, Getreidemarkt 9, 1060 Vienna, Austria.

c AUVA Research Centre, Ludwig Boltzmann Institute for Experimental and Clinical Traumatology, 1200 Vienna, Austria

d Austrian Cluster for Tissue Regeneration, 1200 Vienna, Austria

e Fraunhofer Institute for Biomedical Engineering, 66280 Sulzbach, Germany

*E-mail: mario.rothbauer@tuwien.ac.at, peter.ertl@tuwien.ac.at

$\dagger$ these authors contributed equally

\begin{abstract}
:
Glucose transport is key for cellular metabolism as well as physiological function and is maintained via passive facilitated and active sodium-glucose linked transport routes. Here, we present for the first time Fourier-transform infrared spectroscopy as a novel approach for quantification of apical-to-basolateral glucose transport of in vitro cell barrier models using liver, lung, intestinal and placental cancer cell lines. Results of our comparative study revealed that distinct differences could be observed upon subjection to transport inhibitors.
\end{abstract}

Keywords: FITR, cancer cell barriers, transwell, glucose transport, transport inhibition

(C) 2020. This is the submitted version of the following article: M. Rothbauer, C. Eilenberger, S. Spitz, B. Bachmann, J. Pajenda, A. Schwaighofer, G. Höll, P.S. Helmke, Y. Kohl, B. Lendl, P. Ertl. "FTIR spectroscopy as a novel analytical approach for investigation of glucose transport and glucose transport inhibition studies in transwell in vitro barrier models". 237 (2020) 118388, which has been published in final form at https://doi.org/10.1016/j.saa.2020.118388. This manuscript version is made available under theCC-BY-NC-ND 4.0 license http://creativecommons.org/licenses/by-nc-nd/4.0/ 


\section{Introduction}

The human body relies on glucose as its main source of energy to maintain physiologic tissue, organ and cell function ${ }^{1}$. Dietary uptake of glucose occurs in the digestive tract through intestinal absorption, from where glucose molecules are further distributed via the circulatory system ${ }^{2}$. The distribution process involves epithelial barriers regulating glucose transport either by paracellular or transcellular carrier-mediated transport ${ }^{1,3}$. This carrier-mediated transport of glucose relies on two distinct types of glucose transporter families, whose members can vary in function, tissue distribution and glucose affinity ${ }^{4}$ Within tissue types that are crucial for absorption and reabsorption of glucose (e.g. gut or kidney), active transport against a glucose gradient is achieved by sodium-glucose linked transporters (SGLT) ${ }^{5}$. This type of transporter mediates glucose transport into the epithelium by cotransporting sodium ions from the extracellular space along an established sodium gradient. In contrast, diffusion of glucose along an electrochemical gradient of the monosaccharide is facilitated by the glucose uniporter family (GLUT) ${ }^{6}$, which is ubiquitously distributed among various tissue types such as lung ${ }^{7}$ or placenta ${ }^{8}$. For instance, the most common subtype of the GLUT transporters, GLUT1, is present in the blood-brain-barrier ${ }^{9}$ as well as in various blood-tissue barriers ${ }^{10}$ including the human placenta ${ }^{11}$. Because glucose transporters are of the utmost importance for glucose homeostasis within the human body, mutations thereof can result in several severe diseases. For example, mutations in GLUT2 and GLUT4 genes are linked to diabetes type $\mathrm{II}^{12}$ whereas malfunction of the GLUT1 transporter leads to GLUT1-deficiency syndrome causing neural disorders, seizures and ataxia ${ }^{13}$. Mutations in SGLT1 on the other hand cause fatal malabsorption in the intestines ${ }^{5}$. The prevalence of both GLUTs and SGLTs throughout the human body render them an important target for investigation of cell-based in vitro models. By employing cells of the respective organ, many studies try to recapitulate barrier function and transport in vitro, generating suitable and more physiologically relevant organ models as well as drug testing platforms ${ }^{14}$. Many barrier models make use of cancer cell lines, which provide several advantages such as cost effectiveness, ease of continuous cultivation as well as reproducibility ${ }^{15,16}$. So far, various methods for detection and quantification of glucose have been established including chromatography, mass spectrometry and electrophoresis, as well as enzymatic, enzyme-free and fluorescence-based assays ${ }^{17-19}$. While enzymatic detection systems are specific to glucose and enable relatively high throughput due to a microtiter plate format, non-enzymatic instrumentation such as chromatography and mass spectrometry offer broad applicability due to their ability to simultaneously analyse other analytes ${ }^{20}$. A more detailed overview over the state-of-the-art and progress of glucose monitoring and detailed working principles has been reviewed recently ${ }^{19}$. Routinely, whole blood glucose is detected in the field using electrochemical methods such as amperometry, which, to date, constitutes the most successful and prominent glucose biosensor for point-of-care diagnostics ${ }^{21}$. Fourier-transform infrared (FTIR) spectroscopy is another fast and label-free alternative biosensing approach and has been applied for the detection of glucose from human blood and serum samples among many other samples such as cell culture processes, enzymes and proteins ${ }^{22-27}$. Recently, FTIR spectroscopy has been under investigation as suitable technique for the clinical detection of glucose in vivo, during ex vivo blood dialysis, for monitoring of pro- and eukaryotic bioprocesses and fermentations ${ }^{23,24,28-31}$. However, up to now no study has applied Fourier-transform infrared spectroscopy as a simple and rapid strategy for the assessment of glucose transport levels of in vitro cell barrier models. Therefore, we introduce FTIR spectroscopy for glucose quantification from complex artificial matrices such as cell culture supernatants derived from in vitro barrier models grown in Transwell inserts. After initial characterization of the non-invasive method to detect glucose in standard cell culture medium as well as phosphate buffered saline, FTIR spectroscopy was used to compare the overall glucose transport across several well-established cancer-derived in vitro models including pulmonary, placental, hepatic and intestinal epithelial barriers (for comparison of in vitro and in vivo glucose transporters see Figure 1). The barrier models were first characterized for proper barrier integrity over a time-course of eight days using transepithelial electrical resistance (TEER) 
measurements ${ }^{16}$ as well as metabolic and fluorescent as well as Live/Dead assays. As a proof-of-principle, we apply Fouriertransform infrared spectroscopy in a comparative study of glucose transport and inhibition of pulmonary, placental, and hepatic as well as three different intestinal epithelial barrier models using cytochalasin B (CB) as well as phloretin.

\section{Experimental}

\subsection{Cell Culture}

Placental Bewo cells (kindly provided by Dr. Berthold Huppertz, Medical University of Graz, Austria) were cultivated in Dulbecco's modified Eagle medium (DMEM with L-glutamine and high glucose; Gibco, 11965-084). Intestinal models Caco-2 and HT-29 cells were maintained in DMEM and additionally 1\% non-essential amino acids (NEAA; Gibco, Cat. nr. 11140-035). Hep G2 liver cells were cultured in modified Eagle's medium (MEM) (Sigma Aldrich, M4526). The alveolar cell line A549 cells were cultivated in RPMI 1640 medium (Sigma Aldrich, D5796). All media were supplemented with 10\% FBS and 1\% antibiotic mix. All cells were cultivated in a humidified atmosphere at $37^{\circ} \mathrm{C}$ and $5 \% \mathrm{CO}_{2}$.

\subsection{Preparation of Trans-well Transport Models}

Cells were seeded onto porous polyester trans-well membranes for barrier integrity and glucose transport studies with a growth area of $1.2 \mathrm{~cm}^{2}$, a pore size of $3.0 \mu \mathrm{m}$ and placed in 12-well tissue culture plates (Costar, Greiner BioOne). All cells were seeded with a total seeding density of $1 \times 10^{5}$ cells $/ \mathrm{cm}^{2}$ on the apical side of the permeable membrane inserts on day 0 . The apical chamber was filled with $0.5 \mathrm{ml}$ and the basal compartment with $1.5 \mathrm{ml}$ of the appropriate cell culture medium for each cell type. For the no-cell controls, the respective amount of cell culture medium was filled in the apical and the basal chambers. The medium was refreshed every second day (on day 1, 3, 5 and 7 post seeding).

\subsection{Trans-epithelial electric resistance (TEER) measurements}

All TEER measurements were performed with an EVOM2 voltmeter equipped with a STX2 electrode (World Precision Instruments Ltd). TEER was measured and averaged at three different well positions. Electrodes were immersed in cell culture media before measurements for about 30 minutes, while the device was allowed to warm up. TEER analysis was performed at room temperature after refreshing the medium. The resistance values were expressed as unit area resistance $\left(\Omega * \mathrm{~cm}^{2}\right)$ and therefore data was baseline subtracted from acellular control and multiplied by trans-well area.

\subsection{Cell viability evaluation}

Cell viability was evaluated using a PrestoBlue ${ }^{\mathrm{TM}}$ (Thermo Fisher, 1824890). Cells were seeded in trans-wells at an initial seeding density of $1 * 10^{5}$ cells $/ \mathrm{cm}^{2}$ on 48 -well tissue culture plates. Culture medium was exchanged every other day. On day $1,3,5$ and 7, PrestoBlue assay was performed according to the manufacturer's protocol using $200 \mu \mathrm{l}$ of $10 \%$ detection mix. After an incubation time of 60 minutes at $37^{\circ} \mathrm{C}, 100 \mu \mathrm{l}$ were transferred into 96-well plates and analyzed using an EnSpire 2300 plate reader (Ex. 560 nm/Em. 590 nm; Perkin Elmer). The fluorescence values were averaged, baseline subtracted and expressed as $\%$ viability normalized to day 1 . For a visual inspection of viability, a live/dead staining based on Calcein AM and Ethidium Homodimer-1 (EthD-1) (Thermo Fisher, 1906259) was performed in parallel in collagen-coated 48-well plates. Medium was replaced with a dual staining solution and incubated for 30 minutes in the dark at $37{ }^{\circ} \mathrm{C}$. Images were taken with an IX83 microscope (Olympus, Austria) using GFP (Ex. $495 \mathrm{~nm} / \mathrm{Em} .515 \mathrm{~nm}$ ) and rhodamine (Ex. $495 \mathrm{~nm} /$ Em. $635 \mathrm{~nm}$ ) filter sets. 


\title{
2.5 Preparation of glucose inhibitors
}

Cytochalasin B from drechslera dematioidea (Sigma Aldrich, C6762) was dissolved in dimethyl sulfoxide (DMSO) at a final working concentration of $20 \mu \mathrm{M}$ in the respective full culture medium. Phloretin (Sigma Aldrich, P7912) was dissolved in 99\% ethanol and then further diluted to $30 \mu \mathrm{M}$ with the respective cell culture medium.

\subsection{Evaluation of glucose transport}

Evaluation of the glucose transport was carried out on day 7 post seeding. The apical chamber was filled with $0.7 \mathrm{ml}$ of high

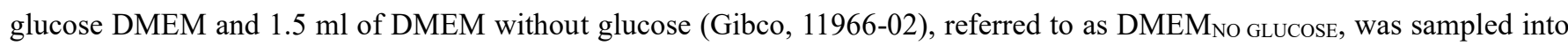
the basal chamber of each transwell. A $50 \mu \mathrm{l}$ sample of the apical and basal compartment was taken at 0,60, 105, and 150 minutes post exposure. Results were dilution corrected for the removal of $50 \mu \mathrm{l}$ for each measurement time point. Acellular control experiments were performed with the respective amount of DMEM $\mathrm{HIGH}_{\text {GLUCOSE }}$ and DMEM $\mathrm{NO}_{\text {GLUCOSE }}$ to monitor maximal possible transport. The basal glucose transport rate was calculated with the formula given in Equation S1. It describes the relation of differences in basal glucose concentrations, $c_{b}$, between two neighboring time points to the according time difference.

\author{
Equation 1: $\quad$ Transport rate $\left(t_{n}\right)=\frac{c_{b}\left(t_{n}\right)-c_{b}\left(t_{n-1}\right)}{t_{n}-t_{n-1}}$ \\ for $0<\mathrm{n}<4 ; \mathrm{t}(\mathrm{n})=\{0,1,1.75,2.5\} \mathrm{h}$
}

For inhibition experiments, cell barriers were treated with the inhibitory substances on day 7 post seeding and incubated for 24 hours in the dark at $37^{\circ} \mathrm{C}$. The transport experiments were conducted on day 8 post seeding. Again, the apical chamber was filled

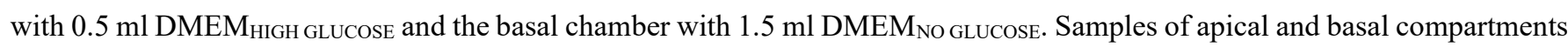
were taken after 2 hour for cells treated with Cytochalasin B or Phloretin. Glucose transport inhibition was expressed as percentage of the untreated cells (controls).

\subsection{Quantification of glucose using FTIR spectroscopy}

Fourier-transform infrared spectroscopy of glucose was performed using a platinum ATR sampling unit on an InfraRed Tensor 37 (Bruker). A $30 \mu 1$ medium sample was pipetted onto the diamond ATR crystal, which was cleaned with ethanol before each measurement. For the reference series, the absorbance spectrum was analysed at the wavelengths of the fundamental vibrations of glucose at $1153 \mathrm{~cm}^{-1}, 1108 \mathrm{~cm}^{-1}, 1080.5 \mathrm{~cm}^{-1}, 1035.7 \mathrm{~cm}^{-1}$ and $994.3 \mathrm{~cm}^{-1}$ of the mid infra-red (MIR) region. Four different dilution series were prepared for the reference series to analyse the impact of different solvents in the absorbance spectrum. The

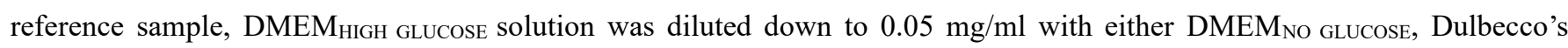
Phosphate Buffered Saline (PBS) without calcium chloride $\left(\mathrm{CaCl}_{2}\right)$ and magnesium chloride $\left(\mathrm{MgCl}_{2}\right) \mathrm{PBS}(\mathrm{Sigma} \mathrm{Aldrich}$, D8537), with $\mathrm{CaCl}_{2}$ and $\mathrm{MgCl}_{2}$ (PBS+; Sigma Aldrich, D8662) or distilled water. Data analysis was performed with OPUS 7.5® software. The measurements were recorded with an average of 200 scans at $2 \mathrm{~cm}^{-1}$ resolution, which resulted in a spectra acquisition time of 170 . seconds. The recorded measurement region covered the mid infrared region from $4000-900 \mathrm{~cm}^{-1}$. The absorbance spectra were smoothed with 9 smoothing points and integrated. For quantitative evaluation, the height of the 
absorption band was analyzed. For glucose transport and inhibition studies the band height was analyzed at the wavenumber of $1035.7 \mathrm{~cm}^{-1}$, if not stated otherwise.

The sensitivity, or slope, $\mathrm{k}$ of linear regression was used for the calculation of the limit of quantification (LOQ) and limit of detection (LOD). The applied formulas are given in Equation S3-4:

Equation 2:

$$
\text { LOD }=3 \frac{\text { RMS noise }}{\mathrm{k}}
$$

Equation 3:

$$
\mathrm{LOQ}=10 \frac{\mathrm{RMS} \text { noise }}{\mathrm{k}}
$$

The root mean square (RMS) noise of the instrument was measured twice from 1200 to $990 \mathrm{~cm}-1$ (with the same number of scans) and averaged and the slope of the calibration line was determined for each absorbance band.

\subsection{Colorimetric glucose assay}

For the colorimetric approach, the same range of glucose concentrations as for infrared spectroscopy was measured. The standard solution of the kit was prepared as per instructions given in the glucose assay kit (Abcam, ab65333). The measurement of standards, controls and samples were assayed in duplicate. The highest glucose concentration detectable by the kit is $200 \mu \mathrm{M}$ $\left(=36 * 10^{-3} \mathrm{mg} / \mathrm{ml}\right)$. For the reference series, first D- $(+)$-Glucose (Sigma Aldrich, Cat. nr. G5400) was dissolved in distilled water, to create sugar solutions with concentrations from $25 \mathrm{mM}$ to $560 \mu \mathrm{M}$. Secondly, the whole reference series was diluted in a ratio of 1:130 to fall below the maximum of $200 \mu \mathrm{M}$ glucose in the standard series. Standard and samples (reference series) were pipetted into a 96-well tissue culture plate. For each measurement $50 \mu \mathrm{l}$ of reaction mix was added into the standard and sample wells. Additionally, $50 \mu \mathrm{l}$ of background reaction mix was into background control wells. The plate was incubated for 30 minutes in the dark at $37^{\circ} \mathrm{C}$ and then analysed with the EnSpire 2300 plate reader (Ex. $535 \mathrm{~nm} / \mathrm{Em} .587 \mathrm{~nm}$; Perkin Elmer).

\subsection{Fluorescence imaging}

For visualization of nuclei and cytoskeleton $6 \mu \mathrm{M}$ FITC-conjugated phalloidin solution (Invitrogen) was added for $1 \mathrm{~h}$ at room temperature followed by the addition of $0.4 \mu \mathrm{g} / \mathrm{ml}$ DAPI (Sigma Aldrich) in DPBS for $5 \mathrm{~min}$. Samples were washed three times with DPBS after each step and embedded in Vectashield ${ }^{\circledR}$ mounting medium (Thermo Fisher) prior to analysis. All images were recorded with in IX83 live-cell microscope (Olympus, Austria) equipped with a Hamamatsu ORCA flash camera.

\subsection{Sodium-fluorescein leakage assay}

For evaluation of barrier integrity with sodium fluorescein leakage assay, first, the basal chamber of the transwell inserts was filled up with $1.5 \mathrm{ml}$ of cell culture medium on day 0 . Next, $1 * 10^{5}$ cells $\mathrm{cm}^{-2}$ in $500 \mu$ l culture medium were seeded onto the 3 $\mu \mathrm{m}$ porous polyester membrane of the apical chamber. For acellular controls, only the respective cell culture medium was pipetted onto the blank membrane filters. At day 3 and 7 post seeding, medium from the apical chamber was aspirated and replaced with $500 \mu \mathrm{l}$ of $100 \mu \mathrm{M}$ sodium fluorescein solution. At each time point, $50 \mu \mathrm{l}$ samples from the basal chamber were pipetted into a 96-well plate and analyzed using an EnSpire 2300 plate reader (Ex. 470/Em. 525; Perkin Elmer). 


\section{Results and discussion}

3.1 Characterization of ATR-FTIR spectroscopy for Transwell-based glucose transport studies

Even though FTIR spectroscopy has been extensively used for quantification of glucose in blood as well as in serum, to date no study has applied this non-invasive and fast label-free method for detection of glucose transport of in vitro cell culture models. Therefore, prior to any cell-based experiment, FTIR spectroscopy was characterized to identify the ideal spectral range and sensitivity for detection of glucose concentrations from complex cell culture media. Glucose was added in different diluents including water, phosphate buffer as well as culture medium. Figure 2A depicts the spectrum of the typical adsorption bands of

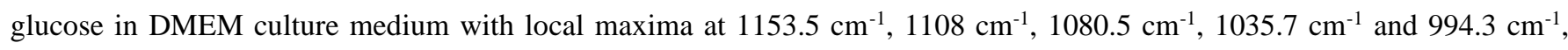
corresponding well with literature ${ }^{32}$. The absorbance values at the band maximum of $1035.7 \mathrm{~cm}^{-1}$ show the highest trend in absorption due to strong vibrational modes in the $\mathrm{C}-\mathrm{O}$ and $\mathrm{C}-\mathrm{C}$ structure of glucose. After this initial assessment, glucose detection via FTIR spectroscopy was benchmarked against state-of-the-art colorimetric assays based on glucose oxidase. For the colorimetric detection of glucose, a reference series in the range of $4.5-0.1 \mathrm{mg} / \mathrm{ml}$ glucose was prepared and further diluted 1:130 to be compatible with the maximum detectable limit of the colorimetric assay. As shown in Figure 2BC, both the absorbance data derived from FTIR spectroscopy of any local maxima and the fluorescence intensities of the colorimetric detection strategy were in good agreement and showed a linear relationship for increasing concentrations of glucose in the range of 0.1 to $4.5 \mathrm{mg} / \mathrm{ml}$. In comparison to the colorimetric detection which resulted in a limit of detection for glucose at approx. $0.018 \mathrm{mg} / \mathrm{ml}$, FTIR spectroscopy at the most sensitive wavenumber $1035 \mathrm{~cm}^{-1}$ revealed a limit of detection of $0.169 \mathrm{mg} / \mathrm{ml}$. In order to investigate the influence of media composition on possible artifacts in the spectrum range of glucose, different dilution series of DMEM containing $4.5 \mathrm{mg} / \mathrm{ml}$ glucose with either glucose-free medium, sterile distilled water or phosphate buffer were investigated. Graphical analysis in Figure 2D revealed no noticeable difference of sensitivity for absorbance data recorded at $1035.7 \mathrm{~cm}^{-1}$ with LODs for glucose of $0.168 \mathrm{mg} / \mathrm{ml}, 0.172 \mathrm{mg} / \mathrm{ml}, 0.170 \mathrm{mg} / \mathrm{ml}$ and $0.164 \mathrm{mg} / \mathrm{ml}$ for DMEM culture medium, deionized water as well as phosphate buffer, respectively. A negligible positive offset for both PBS in the presence and absence of $\mathrm{CaCl}_{2}$ and $\mathrm{MgCl}_{2}$ ions (PBS+/PBS-) can be attributed to phosphate interferences at the wavenumber of $1035.7 \mathrm{~cm}^{-1}$. Even though not as sensitive as colorimetric assays, glucose concentrations present in cell culture supernatants can easily be detected using FTIR spectroscopy without the need for any further laborious dilution or sample preparation steps.

\subsection{Characterization of the Transwell barrier models based on cancer cell lines}

Integrity of the epithelial barrier is the most important feature for the physiological function of any epithelial transport model. Therefore, viability as well as barrier integrity was investigated to ensure proper barrier quality prior to glucose transport experiments. In order to evaluate the integrity and coverage of the cell barriers and rule out holes and barrier ruptures, as quality control TEER analysis was performed over a period of 8 days for pulmonary, placental, hepatic and intestinal in vitro cell models seeded at an initial seeding density of $1 * 10^{5}$ cells $/ \mathrm{cm}^{2}$ in a trans-well set-up. Figure $3 \mathrm{~A}$ shows that over the course of several days, TEER values for all barrier types increased gradually with a unit area resistance on day 7 post seeding peaking at 125.20 $\pm 5.7 \Omega \mathrm{cm}^{2}$ for pulmonary A549 cells, $119.5 \pm 11.6 \Omega \mathrm{cm}^{2}$ for placental Bewo cells, $80 \pm 7.1 \Omega \mathrm{cm}^{2}$ for hepatic Hep G2, $134.6 \pm$

$7.6 \Omega \mathrm{cm}^{2}$ for intestinal Caco-2 cells, $101.3 \pm 13.2 \Omega \mathrm{cm}^{2}$ for intestinal HT29 cells and $171.7 \pm 7.2 \Omega \mathrm{cm}^{2}$ for the co-culture of 
Caco-2 with HT29 cells. Overall, the co-culture of Caco-2 with HT29 cells resulted in the highest increase in TEER, whereas the Hep G2 cell barrier showed the lowest overall TEER value development at day 7 post-seeding. These results indicate that the co-culture of Caco-2 with HT29 cells form a tighter cell barrier in terms of barrier integrity than the individual intestinal barrier models, as well as pulmonary, placental or hepatic barrier cell models. Although Caco-2 and HT29 are both colon carcinoma cells, they show distinct differences in their TEER development. Caco-2 cells display characteristics of colonocyte and enterocyte phenotypes and are known for high TEER values, ${ }^{33}$ whereas HT29 cells display goblet cell properties and produce lower TEER values, which is more physiological when taking in vivo situation into account ${ }^{34}$. Overall, all barrier cell models were considered leakage-free due to gradual increase of resistance over time.

In addition, viability as well as metabolic activity of the barrier models was determined to rule out influences of cell death or loss of barrier integrity for transport studies of glucose from day 7 to day 8 post-seeding. Therefore, a fluorescent live/dead assay (Calcein AM/ethidium bromide) and a metabolic PrestoBlue ${ }^{\mathrm{TM}}$ assay were performed at day 1, 3, 5, 7 and 8 post-seeding (see Figure S1-S2). Even though a few necrotic cells were found floating above tight and healthy cell barriers based on microscopy of the Calcein AM and ethidium bromide dye exclusion assay (red fluorescent cells in Figure S1), no signs of barrier impairment due to cell layer disruption were observable for any cell type. To further analyse barrier health, PrestoBlue ${ }^{\mathrm{TM}}$ assay was performed to give a more quantitative reflection of barrier health based on increase of cell metabolism as a function of cell growth and viable cells over time. The highest metabolic activity was observed for Caco-2 barriers, followed by Bewo and HT29 barriers at day 7 post-seeding and lowest metabolic activity was observed for A549 and HepG2. Overall, all cell lines gradually increased metabolic activity over time indicating good barrier viability ranging from 1.5 to 2.5 -fold of day 1 indicating gradual and steady cell growth of viable barrier cells. It must be noted that loss in cell viability comes a long with decrease of cell metabolism thus significant drop in signal, which is not the case for the presented barrier models. Therefore, the few ethidium positive cells can be considered negligible with respect to barrier health status. When investigating barrier integrity and morphology in more detail using fluorescence staining, confluent cell barriers were already achieved for all cell types as early as day 3 and gradually improving to day 7-8, being in line with TEER analysis (see Figure 3A for confluent barrier models). Differences between individual cancer-derived cell barrier models cultivated under the same cultivation conditions and initial seeding densities were more pronounced at day 7 to 8 when inspecting layer thickness. The results shown in Figure S3BC indicate that thicker barriers were observable for intestinal co-cultures between $37.7 \pm 23.1 \mu \mathrm{m}$ height, whereas placental and hepatic cells showed a height around 25 and $23 \mu \mathrm{m}$, respectively. In contrast, lung A549 showed average height of $3.75 \pm 0.82 \mu \mathrm{m}$ and both intestinal monoculture barriers formed cell layers with a height around $6 \mu \mathrm{m}$ for Caco-2 and $11 \mu \mathrm{m}$ height for HT29 cells. When comparing additional sodium fluorescein leakage assay with previous TEER measurements (see Figure S3D), results revealed steady increase in molecular barrier tightness from day 3 to day 7 post-seeding towards cell-impermeable fluorescein which corresponded well with increase of resistance values. When combining all these characterizations, Transwell barriers with these properties were considered tight and healthy and were as a consequence used for glucose transport studies.

3.3 ATR-FTIR Analysis of glucose transport and transport inhibition using cytochalasin B and phloretin

Next, FTIR spectroscopy was applied in a comparative study to investigate differences in glucose transport through placental, pulmonary, hepatic and intestinal barriers. Therefore, glucose concentrations during the apical-to-basal transport of the trans-well experiment were analyzed over a time course of 150 minutes for each cell barrier model and compared to maximum transport values for acellular controls. Figure 3B displays the time course of glucose concentrations in basolateral trans-well compartments (for more details on the glucose concentrations of each individual barrier model and acellular control samples see Figure S4). During the first hour glucose was rapidly taken up by the barrier cells with gradually declining velocity over time. 
This asymmetric behavior is common for glucose transport in transwell insert systems ${ }^{35}$. All cell barrier models showed gradually increasing values for transported glucose over time with $8.96 \pm 1.64 \mathrm{mmol} / \mathrm{l} / \mathrm{cm}^{2}$ for Caco- $2,7.71 \pm 1.45 \mathrm{mmol} / 1 / \mathrm{cm}^{2}$ for the coculture of Caco-2 and HT29, $7.43 \pm 0.43 \mathrm{mmol} / \mathrm{l} / \mathrm{cm}^{2}$ for Bewo, A549 with $7.33 \pm 1.25 \mathrm{mmol} / 1 / \mathrm{cm}^{2}$, HT29 with $7.28 \pm 1.27$ $\mathrm{mmol} / \mathrm{l} / \mathrm{cm}^{2}$ followed by Hep G2 cells with $6.19 \pm 0.64 \mathrm{mmol} / 1 / \mathrm{cm}^{2}$ in contrast to the acellular control that peaked at $11.25 \pm 1.3$ $\mathrm{mmol} / \mathrm{l} / \mathrm{cm}^{2}$ after 150 minutes. When calculating transport rates, cighest cellular glucose uptake rates were found for Caco-2 with $122.1 \pm 10.4 \mu \mathrm{mol} / \mathrm{l} / \mathrm{min} / \mathrm{cm}^{2}$, Caco-2/HT29 coculture with $102.1 \pm 8.7 \mu \mathrm{mol} / \mathrm{l} / \mathrm{min} / \mathrm{cm}^{2}$ followed by Bewo with $98.9 \pm 12.9$ $\mathrm{mol} / \mathrm{l} / \mathrm{min} / \mathrm{cm}^{2}$, HT19 with $90.8 \pm 15.3 \mu \mathrm{mol} / \mathrm{l} / \mathrm{min} / \mathrm{cm}^{2}$, HepG2 with $80.9 \pm 9.8 \mu \mathrm{mol} / 1 / \mathrm{min} / \mathrm{cm}^{2}$ and A549 with $62.9 \pm 4.5$ $\mu \mathrm{mol} / \mathrm{l} / \mathrm{min} / \mathrm{cm}^{2}$. Overall, the intestinal barriers Caco-2 and co-culture of Caco-2 with HT29 display the fastest glucose uptake thus transfer rates. Surprisingly, the intestinal HT29 monocultures showed slightly slower transfer rates than Caco-2 monocultures as well as the intestinal co-culture. Overall, these results are not surprising, since the primary tasks of intestines is to facilitate the transfer of glucose from the intestinal lumen to the blood ${ }^{36}$. Also, placental barriers exhibited high transfer rates and overshadow the rates of the lung and the hepatic barriers. Again, this aligns with the physiological tissue function of the human placenta as fetal development is sustained throughout gestation by high glucose transport rates ${ }^{8}$. When discussing these values in the light of barrier thickness and TEER, for receptor-mediated glucose transport across transwell in vitro barriers, no correlation between layer thickness and transport rates were found indicating that due to its importance for cell and tissue homeostasis glucose can even pass multi-layered barriers of the intestine, liver and placenta in a fast and efficient manner.

In a final set of experiments, FTIR spectroscopy was utilized to investigate the impact of Cytochalasin B (GLUT inhibitor) and Phloretin (GLUT/SGLT inhibitor) on reduction of glucose transport for the placental, pulmonary, hepatic and intestinal in vitro cell barriers. The individual inhibitors were added at day 7 post seeding and incubated for 24 hours. As shown in Figure 4, exposing in vitro cell barriers to $20 \mu \mathrm{M}$ cytochalasin B resulted in glucose transport reduction of $52.64 \pm 10.87 \%$ for placental barriers, $42.11 \pm 13.08 \%$ for Hep G2 and 34.66 $\pm 12.73 \%$ for A549 suggesting the strong influence of GLUT-1 and GLUT-3 on glucose transport through placental, pulmonary and hepatic barriers. ${ }^{4,12,37,38}$ Lowest inhibition of GLUT-dependent glucose transport was observed for the barriers of Caco-2, Caco-2 / HT29 (co-culture) and HT29 with an overall reduction of $18.67 \pm 7.88 \%, 12.14 \pm 5.53 \%$ and $15.59 \pm 7.32 \%$, respectively. Glucose transport inhibition with $30 \mu \mathrm{M}$ phloretin $(\mathrm{PT})$ as shown in Figure 3B indicates inhibition of SGLT-1 and most GLUTs expressed in cancer cells lines with the exception of GLUT5 (fructose), GLUT-9 (transporter for urate) and GLUT-12. ${ }^{12,39}$ Overall, decreased glucose transport to the basolateral transwell compartment of $20.18 \pm 4.36 \%$ for A549, $38.24 \pm 12.16 \%$ for Bewo and 36.27 $\pm 9.43 \%$ for Hep G2 was observed in comparison to transport inhibition via cytochalasin B. In contrast, higher inhibitory effect for the intestinal barriers including Caco-2 with $45.39 \pm 16.24 \%$, HT29 with $24.53 \pm 12.10 \%$ and co-culture Caco-2 / HT29 with $27.09 \pm 7.94 \%$ were observed. These results indicate a substantial influence of SGLT-1 and GLUT2 transporters on glucose transport in intestinal barrier models ${ }^{40-42}$.

\section{Conclusions}

To conclude, we demonstrated how ATR-FTIR spectroscopy can be applied as a fast, label-free and comparably cheap method for the analysis of receptor-mediated glucose transport across human in vitro cell barriers in transwell assays. In contrast to other routinely used detection methods such as colorimetric or other enzyme-based assays, no sample preparation, dilution or sophisticated data analysis is necessary to determine conclusive results on glucose level in both apical and basal trans-well compartments. Furthermore, in a comparative study we have demonstrated how ATR-FTIR spectroscopy can be used for the investigation and characterization of glucose transport and drug-mediated inhibitory effects thereof across a variety of cell-based in vitro barrier models, highlighting the broad applicability of the presented analytical approach. 


\section{Conflicts of interest}

There are no conflicts to declare.

\section{Funding}

This project has received funding from the European Union's Horizon 2020 research and innovation programme under grant agreement No. 685817.

\section{Notes and references}

1. A. Scheepers, H. G. Joost and A. Schurmann, JPEN J Parenter Enteral Nutr, 2004, 28, 364-371.

2. J. Dyer, K. Daly, K. S. Salmon, D. K. Arora, Z. Kokrashvili, R. F. Margolskee and S. P. Shirazi-Beechey, Biochem Soc Trans, 2007, 35, 1191-1194.

3. J. R. Turner, Adv Drug Deliv Rev, 2000, 41, 265-281.

4. R. Augustin, IUBMB life, 2010, 62, 315-333.

5. D. Deng and N. Yan, Protein Sci, 2016, 25, 546-558.

6. M. Uldry and B. Thorens, Pflugers Arch, 2004, 447, 480-489.

7. J. P. Garnett, E. H. Baker and D. L. Baines, The European respiratory journal, 2012, 40, 1269-1276.

8. T. Jansson, M. Wennergren and N. P. Illsley, The Journal of clinical endocrinology and metabolism, 1993, 77, 15541562.

9. S. Morgello, D. Wolfe, E. Godfrey, R. Feinstein, M. Tagliati and D. M. Simpson, Acta Neuropathol, 1995, 90, 366374.

10. C. C. Barron, P. J. Bilan, T. Tsakiridis and E. Tsiani, Metabolism, 2016, 65, 124-139.

11. N. P. Illsley, Placenta, 2000, 21, 14-22.

12. M. Mueckler and B. Thorens, Molecular aspects of medicine, 2013, 34, 121-138.

13. K. Brockmann, Brain Dev, 2009, 31, 545-552.

14. C. M. Sakolish, M. B. Esch, J. J. Hickman, M. L. Shuler and G. J. Mahler, EBioMedicine, 2016, 5, 30-39.

15. M. A. Deli, C. S. Abraham, Y. Kataoka and M. Niwa, Cell Mol Neurobiol, 2005, 25, 59-127.

16. B. Srinivasan, A. R. Kolli, M. B. Esch, H. E. Abaci, M. L. Shuler and J. J. Hickman, J Lab Autom, $2015,20,107-126$.

17. H.-C. Wang and A.-R. Lee, Journal of Food and Drug Analysis, 2015, 23, 191-200.

18. K. Tian, M. Prestgard and A. Tiwari, Materials Science and Engineering: C, 2014, 41, 100-118.

19. W. Villena Gonzales, A. T. Mobashsher and A. Abbosh, Sensors (Basel), 2019, 19.

20. A. L. Galant, R. C. Kaufman and J. D. Wilson, Food Chem, 2015, 188, 149-160.

21. S. A. Zaidi and J. H. Shin, Talanta, 2016, 149, 30-42.

22. Y. C. Shen, A. G. Davies, E. H. Linfield, T. S. Elsey, P. F. Taday and D. D. Arnone, Physics in Medicine and Biology, 2003, 48, 2023-2032.

23. S. De Bruyne, M. M. Speeckaert and J. R. Delanghe, Crit Rev Clin Lab Sci, 2018, 55, 1-20.

24. O. Klein, A. Roth, F. Dornuf, O. Scholler and W. Mantele, Z Naturforsch B, 2012, 67, 1005-1015.

25. M. Rhiel, P. Ducommun, I. Bolzonella, I. Marison and U. von Stockar, Biotechnol Bioeng, 2002, 77, $174-185$.

26. R. C. Rowland-Jones, F. van den Berg, A. J. Racher, E. B. Martin and C. Jaques, Biotechnol Prog, $2017,33,337-346$.

27. H. Q. Wu, E. Read, M. White, B. Chavez, K. Brorson, C. Agarabi and M. Khan, Front Chem Sci Eng, 2015, 9, 386406.

28. T. Vahlsing, S. Delbeck, J. Budde, D. Ihrig, S. Leonhardt and H. M. Heise, Reliable glucose monitoring by ex-vivo blood microdialysis and infrared spectrometry for patients in critical care, SPIE, 2017.

29. T. Vahlsing, S. Delbeck, J. Budde, D. Ihrig and H. M. Heise, Combination of micro-dialysis and infrared spectroscopy: a multianalyte assay for accurate biofluid analysis and patient monitoring, SPIE, 2016.

30. D. Landgrebe, C. Haake, T. Hopfner, S. Beutel, B. Hitzmann, T. Scheper, M. Rhiel and K. F. Reardon, Appl Microbiol Biotechnol, 2010, 88, 11-22.

31. S. A. Arnold, J. Crowley, N. Woods, L. M. Harvey and B. McNeil, Biotechnol Bioeng, 2003, 84, 13-19.

32. M. A. Ibrahim, M. Allam, H. El-Haes, A. F. Jalbout and A. de Leon, Eclética Química Journal; Vol 31, No 3 (2006): Eclética Química, 2018.

33. M. J. Engle, G. S. Goetz and D. H. Alpers, J Cell Physiol, 1998, 174, 362-369.

34. J. Bourgine, I. Billaut-Laden, M. Happillon, J. M. Lo-Guidice, V. Maunoury, M. Imbenotte and F. Broly, Drug Metab Dispos, 2012, 40, 694-705.

35. X. Huang, M. Luthi, E. C. Ontsouka, S. Kallol, M. U. Baumann, D. V. Surbek and C. Albrecht, Mol Hum Reprod, 2016, 22, 442-456. 
L. Chen, B. Tuo and H. Dong, Nutrients, 2016, 8, 43.

37. K. Brown, D. S. Heller, S. Zamudio and N. P. Illsley, Placenta, 2011, 32, 1041-1049.

38. A. Carruthers and A. L. Helgerson, Biochemistry, 1991, 30, 3907-3915.

39. V. Douard and R. P. Ferraris, American journal of physiology. Endocrinology and metabolism, 2008, 295 , E227-237.

40. Y. Zheng, J. S. Scow, J. A. Duenes and M. G. Sarr, Surgery, 2012, 151, 13-25.

41. A. Carruthers, J. DeZutter, A. Ganguly and S. U. Devaskar, American journal of physiology. Endocrinology and metabolism, 2009, 297, E836-848.

42. M. Raja, T. Puntheeranurak, P. Hinterdorfer and R. Kinne, in Current Topics in Membranes, ed. M. O. Bevensee, Academic Press, 2012, vol. 70, pp. 29-76.

\section{Glucose transporters in human tissue versus cell-based barrier in vitro models}

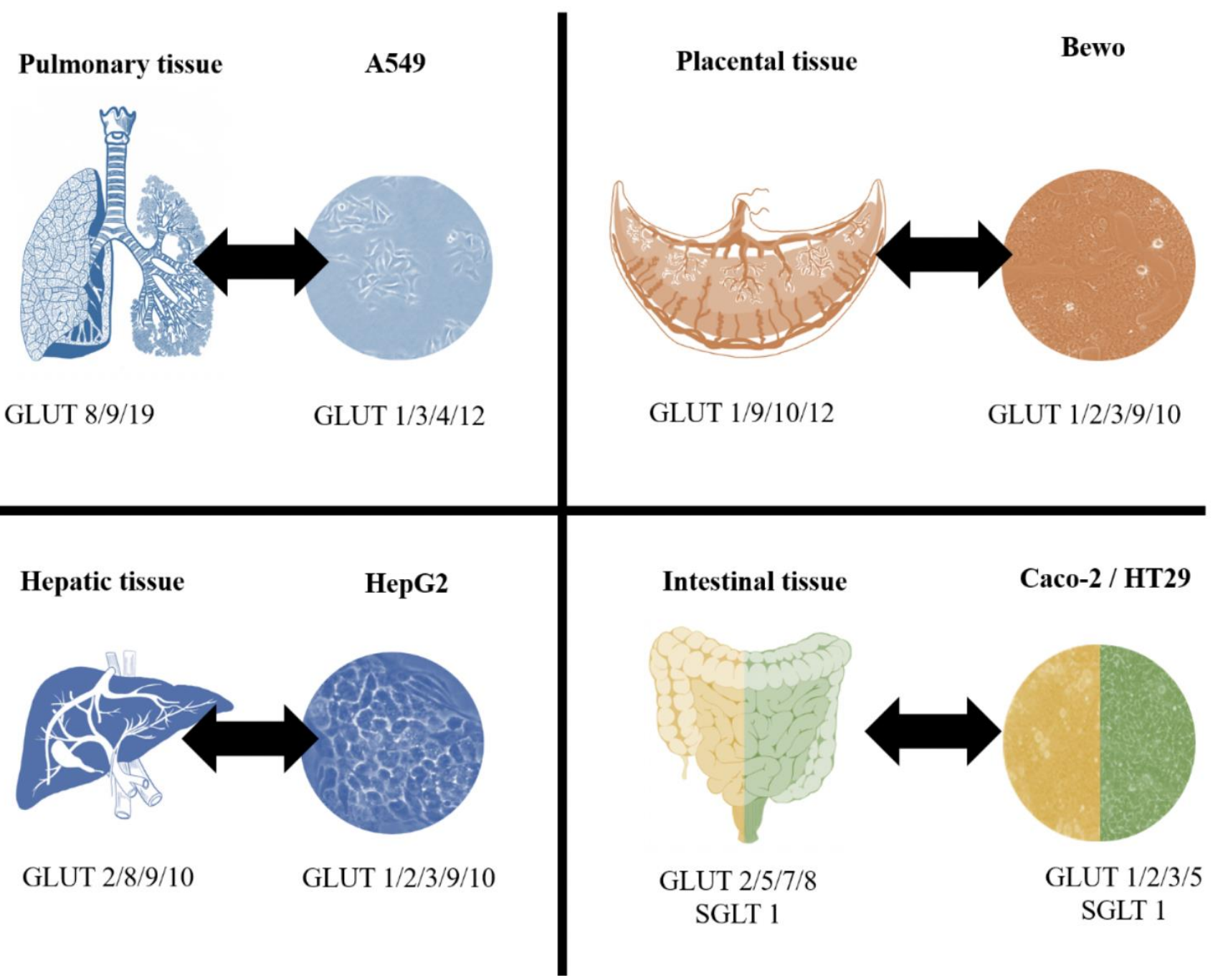

Figure 1: (A) Overview of glucose transporters found in human tissue compared to in vitro cell lines including pulmonary A549, placental Bewo, hepatic HEPG2 as well as intestinal HT29 and Caco-2 cell lines. 
A

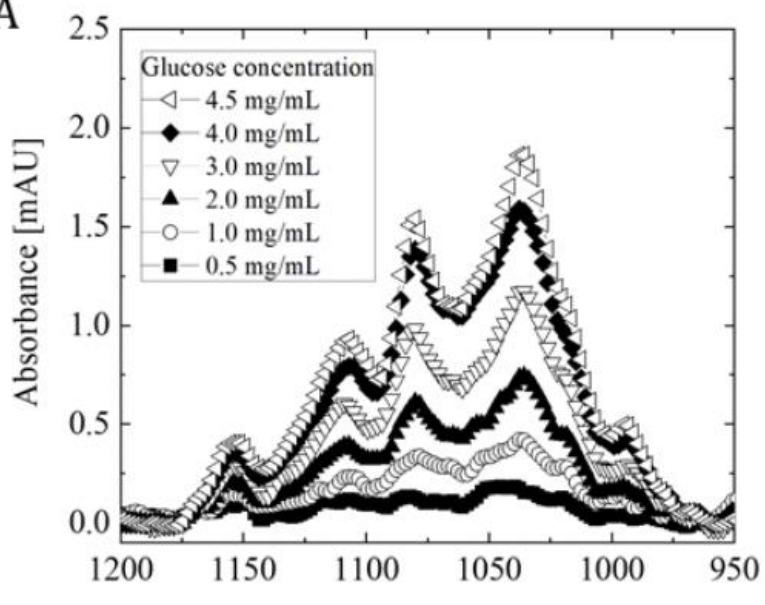

C

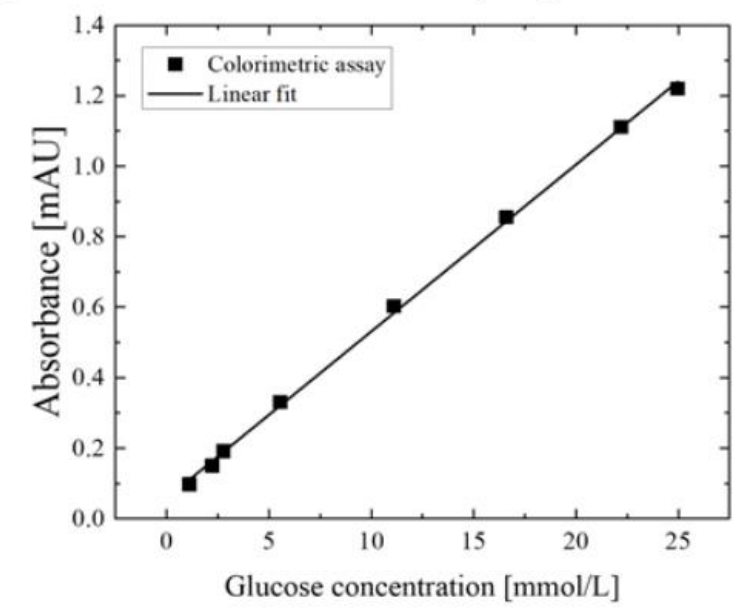

B

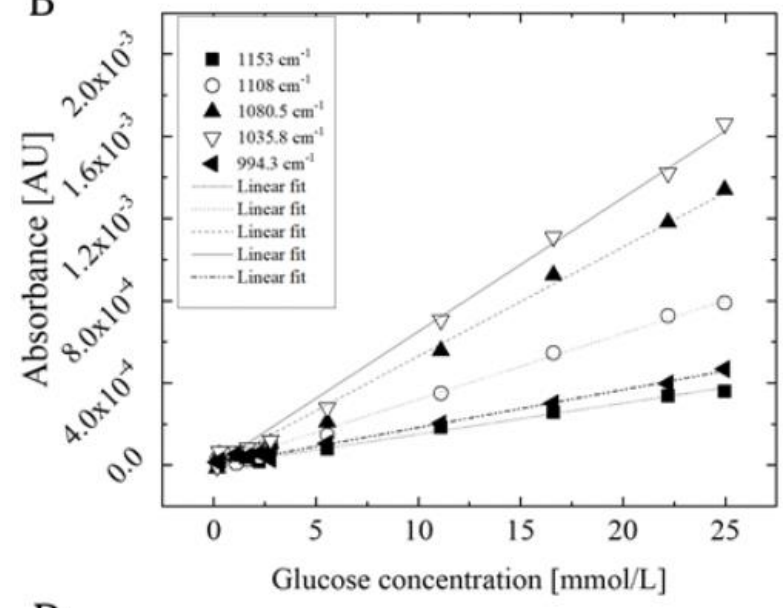

D

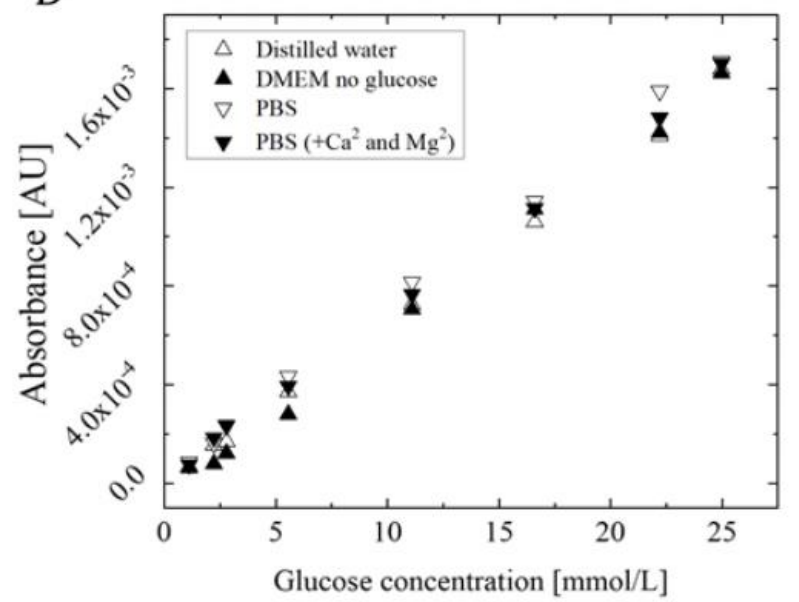

Figure 2. (A) Glucose absorbance spectrum of the FTIR spectroscopy. The smoothed and integrated spectra is shown in the range of $1180 \mathrm{~cm}-1$ to $960 \mathrm{~cm}-1$ for different glucose concentrations in DMEM solutions (B) Comparison of absorbance data from FTIR spectroscopy for the wavenumbers $1153.5 \mathrm{~cm}-1,1108 \mathrm{~cm}-1,1080.5 \mathrm{~cm}-1,1035.7 \mathrm{~cm}-1$ and $994.3 \mathrm{~cm}-1$ and (C) fluorescence intensity of the enzymatic glucose assay are plotted against the corresponding glucose concentrations. Linear regression line is included. (B,C). Absorbance data of FTIR spectroscopy is plotted against corresponding glucose concentrations at the wavenumber $1035.7 \mathrm{~cm}-1$. DMEMHIGH GLUCOSE was diluted with either DMEMNO GLUCOSE, distilled water, PBS+ or PBS-. Linear regression line for each dilution series is included. (D) Impact of matrix on glucose quantification glucose concentrations at the wavenumber $1035.7 \mathrm{~cm}-1$. 
A

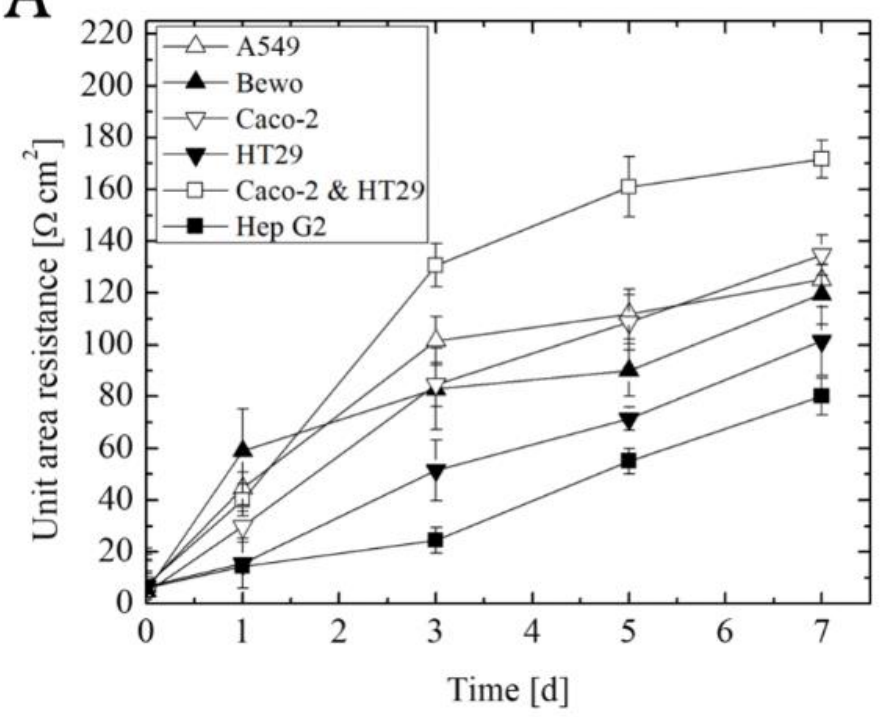

B

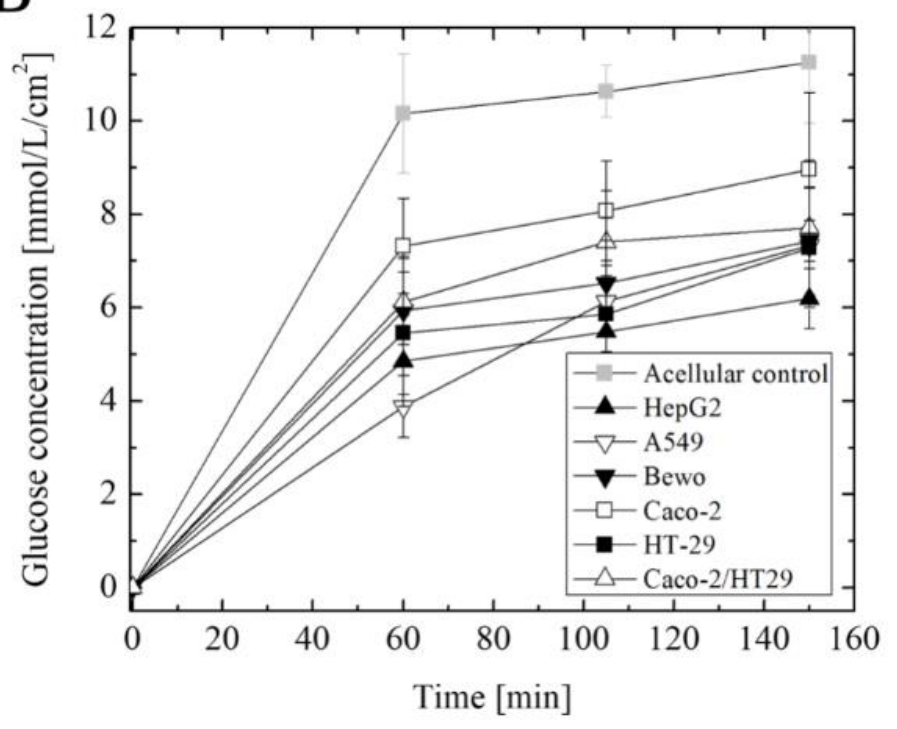

Figure 3 (A) Barrier integrity based on the trans-epithelial electrical resistance of lung A549, placenta Bewo, liver HepG2, as well as intestinal Caco-2 and HT29 mono- and co-cultures (co-culture ratio of 90 \% Caco-2 + 10\% HT29). TEER was measured at day 1, 3, 5 and 7 post seeding after fresh medium exchange at room temperature and is expressed as unit area resistance in $\Omega \mathrm{cm}^{2}$ for $\mathrm{n}=3$ with three positions analysed per transwell insert. (B) Basolateral glucose concentrations over a time course of $150 \mathrm{~min}$ for all barrier models and acellular control trans-wells at day 7 post seeding. Data is expressed as mean values \pm standard deviation for $\mathrm{n}=3$. 


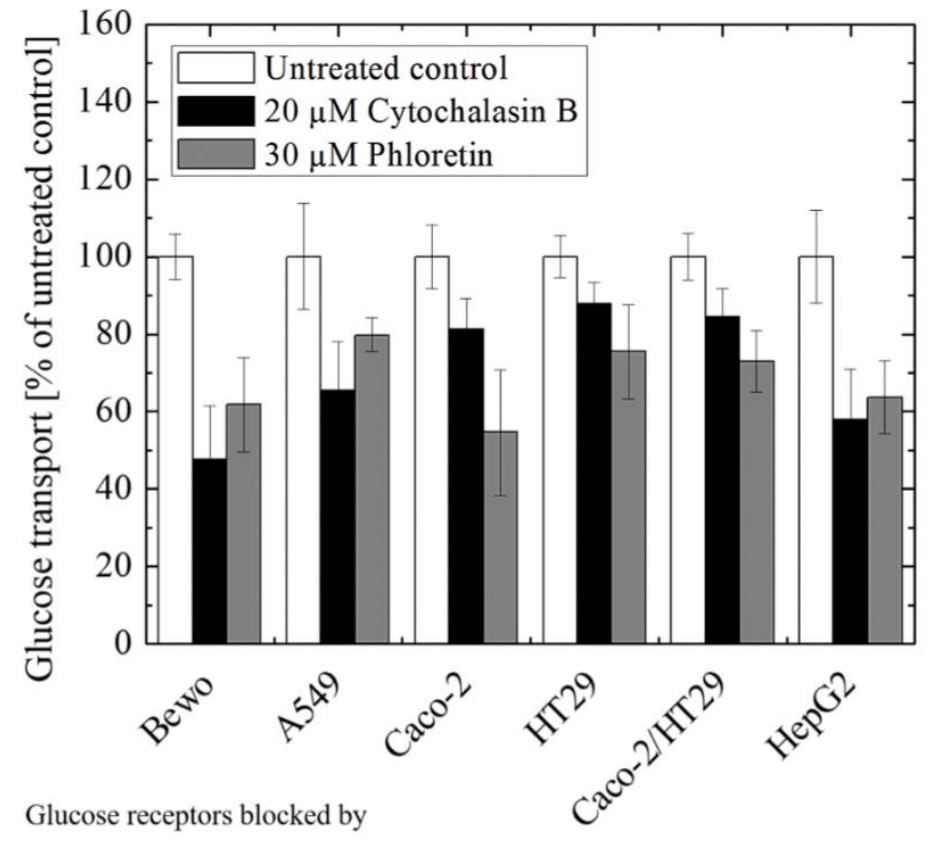

\begin{tabular}{|c|c|c|c|c|c|}
\hline$\underline{\text { Cytochalasin B }}$ & & GLUT-1 & GLUT-1 & GLUT-1 & GLUT-1 \\
\hline & GLUT-1 & GLUT-2 & GLUT-2 & GLUT-2 & GLUT-2 \\
\hline & GLUT-3 & GLUT-3 & GLUT-3 & GLUT-3 & GLUT-3 \\
\hline GLUT-1 & GLUT-4 & GLUT-5 & GLUT-5 & GLUT-5 & GLUT-9 \\
\hline GLUT-3 & GLUT-12 & SLGT-1 & SLGT-1 & SLGT-1 & GLUT-10 \\
\hline Phloretin & & GLUT-1 & GLUT-1 & GLUT-1 & GLUT-1 \\
\hline & GLUT-1 & GLUT-2 & GLUT-2 & GLUT-2 & GLUT-2 \\
\hline & GLUT-3 & GLUT-3 & GLUT-3 & GLUT-3 & GLUT-3 \\
\hline GLUT-1 & GLUT-4 & GLUT-5 & GLUT-5 & GLUT-5 & GLUT-9 \\
\hline GLUT-3 & GLUT-12 & SLGT-1 & SLGT-1 & SLGT-1 & GLUT-10 \\
\hline
\end{tabular}

Figure 4 Inhibitory effect of $20 \mu \mathrm{M}$ Cytochalasin B and $30 \mu \mathrm{M}$ Phloretin on glucose transport across pulmonary A549, placental BeWo, hepatic Hep G2, as well as intestinal Caco-2 and HT29 mono- and co-cultures at day 8 post-seeding. Inhibited glucose transport receptors are summarized under the graph for Cytochalasin B and Phloretin. Data is expressed as \% of untreated control for $n=3$. 